The authors are with the Department of Sports Health and Exercise, School of Life Sciences, University of Hertfordshire, UK.

Richardson, Hughes, and Mitchell

Center of Pressure During Putting

\title{
Center of Pressure Excursion During the Golf Putting Stroke in Low, Mid and High Handicap Golfers.
}

\author{
Ashley K. Richardson, Gerwyn Hughes, and Andrew C S. \\ Mitchell \\ University of Hertfordshire
}

\begin{abstract}
Golf handicap is significantly correlated to putting performance with low handicap golfers (LH) demonstrating increased putting accuracy compared with high handicap golfers (HH). Smaller center of pressure excursion (CPE) during putting has been demonstrated by LH golfers, suggesting balance is important during successful putts. The aim of this study was to examine CPE in low, mid and high handicap golfers about the mediolateral axis (ML) and anteriorposterior axis (AP). Nineteen subjects participated in the study; subjects were split into LH, mid handicap and $\mathrm{HH}$ groups. Subjects completed five successful $2.5 \mathrm{~m}$ putts, standing on an RS FootScan. The LH group demonstrated significantly smaller $\mathrm{CPE}$ in comparison with the $\mathrm{HH}$ group about the AP axis, for all three phases of the putt. No significant differences were found between the groups about the ML axis. The reduction of $\mathrm{CPE}$ about the $\mathrm{AP}$ axis suggests increased balance in that direction, which may contribute to increased accuracy. Coaches should place emphasis on reducing CPE about the AP axis, consequently increasing balance during the putting stroke.
\end{abstract}

Keywords: biomechanics, centre of pressure, golf, golf putt, putting, weight distribution.

The putting stroke is one of several different types of golf shot including driving, iron shots, pitch shots and chips around the green. Pelz (2000) states that putting accounts for $43 \%$ of shots made, highlighting the importance of this aspect of the game.

A number of studies have examined the correlation between putting and overall performance (Dorsel \& Rotunda, 2001; Quinn, 2006; Wiseman \& Chatterjee, 2006). Wiseman and Chatterjee (2006) reported a strong correlation $(r=.68)$ between putting performance and scoring average in professional players competing on the PGA tour over a fourteen-year period from 1990 to 2004. Quinn (2006) found 
putts per green in regulation showed a stronger correlation to scoring average than total putts per round ( $r=.31$ vs $r=.63$ ) based on the top 196 players on the PGA Tour 2004. However, as Hurrion and Hurrion (2008) state, the putting stroke still remains the area of the game least taught.

MacKenzie and Sprigings (2005) state that a number of elements are needed to hit a successful putt, firstly the golfer must correctly read the green to determine the optimal speed, and decide on the correct target line based on the optimal speed with which to project the ball. During execution of the putting stroke, at impact, the putter head should only have horizontal velocity in the direction of the target line; the plane of the putter face then will be perpendicular to that line (MacKenzie \& Sprigings, 2005). Putting in golf is therefore an impact movement where force is applied via a putter to a stationary ball. If the force applied to the stationary ball is of the correct magnitude and in the appropriate direction, then the ball will hit or remain close to the target (Schmidt, Zelaznik, Hawkins, Frank and Quinn, 1979; Sim \& Kim, 2010). In putting, the time of impact is extremely short, therefore the velocity of the putter at impact is extremely important in achieving accuracy in regards to distance and not direction (Sim \& Kim, 2010).

Previous research has shown expert players to demonstrate a slower putter head velocity at impact compared with novice golfers (Delay, Nougier, Orliaguet and Coello, 1997; Sim \& Kim, 2010). It is suggested that expert players hit the ball in a fashion where more kinetic energy is transferred from putter to the ball at impact whereas more energy is lost at impact in novice players (Delay et al., 1997), this is likely due to expert players reducing the number of miss-hits. A potential contributing factor of this is discussed by Delphinus and Sayers (2012), whereby in more proficient golfers the center of mass predominantly moves through the frontal plane about the mediolateral (ML) axis flattening the swing arc increasing the effective impact area and accuracy

Along with impact velocity, studies have shown center of pressure excursion (CPE) to influence putting accuracy (Hurrion and Hurrion, 2008; McLaughlin, Best $\&$ Carlson, 2008). The center of pressure (CP) refers to the point where the total of the pressure fields acts, if concentrated in one point (Ruhe, Fejer \& Walker, 2011). Hurrion and Hurrion (2008) examined total CPE with no regards to whether this was about the ML or anteroposterior (AP) axis in 30 professional European Tour golfers and 30 low handicap golfers ( +3 to 9 handicap) using a RS FootScan pressure mat sampling at $125 \mathrm{~Hz}$. Professionals demonstrated significantly less total CPE of 64.34 $\pm 6 \mathrm{~mm}$ compared with $83.10 \pm 6 \mathrm{~mm}$ for amateurs for a flat $7.62 \mathrm{~m}$ putt with a stimpmeter rating of 12 . The professional group demonstrated significantly less CPE during the start to top of backswing phase $(12.24 \pm 2 \mathrm{~mm})$ compared with the amateur group $(17.61 \pm 3 \mathrm{~mm})$. This was also apparent in the impact to followthrough phase with the professional demonstrating a CPE of $41.97 \pm 5 \mathrm{~mm}$ compared with the amateur group with $53.26 \pm 5 \mathrm{~mm}$. No significant differences were observed in CPE between the two groups for the top of backswing to impact phase. In addition, Hurrion and Hurrion (2008) found the professional group to have a weight distribution of $50 \%$ left and $50 \%$ right split during set up in contrast to the amateur group who demonstrated a $40 \%$ left and $60 \%$ right split.

McLaughlin, Best and Carlson (2008) found a similar trend regarding CPE using a pliance pressure mat sampling at $38.5 \mathrm{~Hz}$. A total of 38 golfers completed a 4 $\mathrm{m}$ putt, split into three groups (low, $n=10$, handicap 0-9; middle, $n=14$, handicap 
10-18; high $n=13$, handicap 18-27). Results showed that low handicap (LH) golfers demonstrated significantly less CPE about the ML axis during the start to top of backswing phase $(4.6 \pm 2.9 \mathrm{~mm})$ in comparison with a high handicap $(\mathrm{HH})$ group $(7.7 \pm 6.2 \mathrm{~mm})$. Similarly the $\mathrm{HH}$ group demonstrated significantly greater CPE $(10.7 \pm 9.0 \mathrm{~mm})$ about the ML axis during the top of backswing to impact phase in comparison with the LH group $(4.5 \pm 4.2 \mathrm{~mm})$. No significant differences were found between the groups for the impact to follow-through phase. McLaughlin et al. (2008) suggest that low handicap golfers are more able to control CPE in the ML axis when putting compared with the mid handicap group $(\mathrm{MH})$ and $\mathrm{HH}$ group.

These findings from Hurrion and Hurrion (2008) and McLaughlin et al., (2008) suggest that golfers with lower handicaps demonstrate reduced CPE throughout the putting stroke which suggests increased CPE is associated with less accurate putting. In addition reduced CPE may result in a more consistent impact point between the putter and ball. The consistent impact point between the putter face and ball may result in less energy loss at impact for LH golfers, allowing more proficient golfers to have a lower putter head velocity at impact, as found by Delay et al. (1997) and Sim \& Kim (2010). However at present no studies have reported $\mathrm{CPE}$ about the AP axis, or have isolated CPE for the left and right foot. In addition, previous studies have not reported CPE on putts of a short to medium length.

Therefore, the aim of this study was to examine CPE about the ML axis and AP axis in low, mid and high handicap golfers during a $2.5 \mathrm{~m}$ flat putt and whether this affects weight distribution during 4 swing events (start, top of backswing, impact and follow-through) during the putting stroke. Weight distribution is defined as the proportion of total body weight that is supported by each foot and specific areas of each foot; whereby which segment of each foot the subject is supporting their mass through. It was hypothesized that golfers with a lower handicap would demonstrate smaller CPE about the ML and AP axis than golfers that have a higher handicap. The reduction of CPE would suggest reduced movement of the golfer's center of gravity, showing that they are therefore more static during putting. This will increase balance during the golf putt, which is defined as the ability of an individual to control equilibrium.

\section{Methods}

\section{Participants}

Following institutional ethical approval, a total of 19 active golfers participated in the study [LH $(n=7)$, age $33.9 \pm 15.2$, height $1.77 \pm 0.04 \mathrm{~m}$, mass $84.6 \pm 19.0 \mathrm{~kg}$, handicap $5.4 \pm 2.9$; $\mathrm{MH}(n=5)$, age $30.0 \pm 15.0$, height $1.77 \pm 0.1 \mathrm{~m}$, mass $79.1 \pm$ $18.1 \mathrm{~kg}$, handicap $16.6 \pm 0.6$; HH $(n=7)$, age $20.1 \pm 1.8$, height $1.81 \pm 0.07 \mathrm{~m}$, mass $70.9 \pm 6.9 \mathrm{~kg}$, handicap $25.9 \pm 2.5$ ]. All golfers were right handed and played golf a minimum of once a week. Subjects wore their own personal golfing attire and golf shoes. Signed informed consent was gained before testing.

\section{Experimental set-up}

A Huxley Golf (Huxley Golf, Hampshire, UK) artificial putting green was used $(3.66 \times 4.27 \mathrm{~m})$ with a stimpmeter rating of 11 . A level $2.5 \mathrm{~m}$ putt was set up with a regulation hole (diameter $108 \mathrm{~mm}$ ). Each participant was asked to use their own 
personal putter due to the large variance of putters available on the current market, and all participants used Srixon Z-STAR golf balls (Srixon Sports Europe Ltd., Hampshire, UK). A $50 \times 32 \mathrm{~cm}$ RS Scan FootScan pressure plate (RS Scan INTERNATIONAL., Olen, Belgium) with a total 4096 sensors, sampling at $100 \mathrm{~Hz}$ was used to record CPE movements during the putting stroke. The sampling rate of $100 \mathrm{~Hz}$ was selected due to a limitation in the RS Scan software allowing for a 10second recording period, which enabled the participant ample time to complete the putt. A Sony HDR-XR155E Handycam sampling at $50 \mathrm{~Hz}$ was positioned $90^{\circ}$ to the path of the golf ball and was level with the artificial putting surface. This gave a clear view of the setup, top of backswing, impact and follow-through (Figure 1), which was used in further analysis to break the putting stroke into phases. The RS Scan FootScan pressure plate and video camera were time synchronized using a LED light via an external synchronization trigger.

\section{[ID]FIG1[/ID]}

\section{Procedure}

The subjects were allowed as much time as they required to familiarize themselves with the putting task. Before the first putting trial the subject was asked to line up the putt. The pressure plate was then placed parallel to the putting line to ensure the feet were aligned to allow for further analysis. Subjects then took up their putting stance on the pressure plate and were required to complete five successful putts. All unsuccessful putts were excluded from the analysis as certain subjects had a $100 \%$ success rate. However the number of unsuccessful putts was recorded to determine each groups putting success rate. Subjects were encouraged to make the putting trial as similar to their putting routine during a real round of golf.

\section{Data Processing}

After processing the digital film to a file type recognized by video analysis software MaxTRAQ Educational 2.12d (Innovation Systems Inc.) putting stroke files were then divided into three phases (Figure 1).

The CPE was calculated as the range of movement of the $\mathrm{CP}$ in two directions (anterior, posterior, left and right) which was then totaled for all given movement about a plane of motion (AP and ML axis). The CPE pattern was calculated by determining the distance of the $\mathrm{CP}$ along the AP axis and ML axis against the average of origin for each phase (average $\mathrm{CP}$ across the phase), giving $\mathrm{X}$, and $\mathrm{Y}$ coordinate which then were plotted to establish each handicap group's pattern. Zero CP refers to the data point before the initiation of Phase 1 .

Weight distribution was calculated by splitting the foot into forefoot $(50 \%)$ and heel $(50 \%)$ (Figure 2) of total foot length, the contact pressure was then converted into percentages for each section (left forefoot, left heel, right forefoot and right heel).

[ID]FIG2[/ID]

\section{Statistical Analysis}

Using statistical software package SPSS 19.0 (SPSS, Inc., Chicago, IL, USA) data were first tested for normality (Shapiro-Wilk $p<.05$ ). All data were found to be 
normally distributed. Following this a one-way between samples ANOVA was used to test for differences between the three subject groups ( $\mathrm{LH}, \mathrm{MH}$ and $\mathrm{HH}$ ) of $\mathrm{CPE}$ ML and AP in the three phases of the putt. A LSD post hoc test was used to determine between which groups the differences lie. Level of significance was set at $p<.05$

\section{Results}

\section{Putting Proficiency}

Significantly higher putting success rates were found for the LH group (81.4\%) in comparison with the $\mathrm{MH}(67.6 \%, p=.013)$ and $\mathrm{HH}$ groups $(53.8 \%, p<.001)$, additionally the $\mathrm{MH}$ group was found to be significantly more proficient than the HH group $(p=.001)$.

[ID]FIG3[/ID]

\section{Weight Distribution}

No significant differences were observed between the three groups for weight distribution at all swing events. The averages (\%) for all the groups combined at the four swing events were [Start; Left $=52.36 \pm 7.35$, Right $=47.64 \pm 7.35$, Anterior $=$ $57.75 \pm 20.28$, Posterior $=42.52 \pm 20.02$; Top of back swing; Left $=53.61 \pm 7.10$, Right $=46.39 \pm 7.10$, Anterior $=57.43 \pm 20.06$, Posterior $=42.52 \pm 20.02$; Impact; Left $=54.23 \pm 6.87$, Right $=45.77 \pm 6.87$, Anterior $=55.89 \pm 19.18$, Posterior $=$ $44.11 \pm 19.18$; Follow-through; Left $=53.35 \pm 7.70$, Right $=46.65 \pm 7.70$, Anterior $=54.80 \pm 18.43$, Posterior $=45.20 \pm 18.43$ ]. This may be due to the large ranges observed within the subject group. In addition at set up weight supported on the forefoot had a range of $19-93 \%$ and interestingly the two extremes were observed in the LH group. Throughout the putting stroke there was a slight favorability to support weight on the left foot and forefoot. The only exclusion to this trend was the $\mathrm{HH}$ group during set up by supporting $50.62 \%$ of total body weight on the right foot.

\section{Centre of Pressure Excursion}

Group means for whole body, left and right CPE during all three phases of the golf putt are displayed in Table 1.

\section{Phase 1: Start to Top of Backswing.}

Low handicap golfers demonstrated significantly less total CPE about the AP axis in comparison with the $\mathrm{HH}$ group ( $p=.027$ ), with the HH group demonstrating 4.07 $\mathrm{mm}$ greater CPE (Table 1). For the left foot the LH group demonstrated significantly less CPE about the AP axis than the HH group $(p=.002)$ and $\mathrm{MH}(p=.041)$ group. For the right foot the LH group demonstrated significantly less CPE about the AP axis when compared with the MH group $(p=.037)$.

$[\mathrm{ID}] \mathrm{TBL} 1[/ \mathrm{ID}]$

Phase 2: Top of Backswing to Impact 
Significantly less total CPE was demonstrated by the LH group about the AP axis in comparison with the HH group $(p=.022)$, the $\mathrm{HH}$ group demonstrated $7.19 \mathrm{~mm}$ greater CPE (Table 1). No significant differences were found for total CPE about the ML axis. For the left foot the LH group demonstrated significantly less CPE about the $\operatorname{AP}(p=.008)$ and ML axis $(p=.036)$ in comparison with the HH group. For the right foot, the LH group demonstrated significantly less CPE about the AP axis when time normalized in comparison with the HH group $(p=.007)$.

\section{Phase 3: Impact to Follow-Through}

Low handicap golfers demonstrated significantly less total CPE about the AP axis in comparison with the HH group $(p=.011)$, the $\mathrm{HH}$ group demonstrated $8.61 \mathrm{~mm}$ greater CPE (Table 1). No significant differences were found for total CPE about the ML axis. For the left foot the LH group demonstrated significantly less CPE about the AP axis than the HH group $(p=.002)$. The LH group also demonstrated significantly less CPE about the ML axis in comparison the HH group $(p=.022)$. For the right foot significantly less CPE was demonstrated by the LH group for CPE about the AP axis $(p=.007)$.

\section{Relative Center of Pressure Excursion Patterns}

\section{[ID]FIG4[/ID]}

Figure 4 displays relative CPE patterns for the three phases of the putt. Visually, it is apparent the HH group has more movement about the AP axis for all three phases of the golf putt; the LH group appears to control movement about the AP axis limiting excursions about the ML axis. The CPE pattern was independent of putter head movement in phase 2 of the putt, all three groups demonstrated a pattern in a right direction (toward the rear foot), in phase 1 and 3 the CPE pattern moves in the same direction as the putter. The HH group however, show CPE back toward the rear foot in a right direction at the end of phase 3 while the putter would be moving in the opposite direction.

\section{Discussion}

The aims of the study were to examine CPE about the ML axis and AP axis in low, mid and high handicap golfers during a $2.5 \mathrm{~m}$ level putt. Significantly higher putting success rates were found for the LH group in comparison with the $\mathrm{MH}$ and $\mathrm{HH}$ groups, the $\mathrm{MH}$ group was also found to be significantly more proficient than the HH group also, suggesting that the subjects' handicap reflected their ability. The results showed that the LH group demonstrated significantly less CPE about the AP axis in comparison with the HH group for all three phases of the golf putt. No significant differences were found about the AP axis between the MH group with either the HH group or LH group, and therefore other factors must contribute to what makes the LH group more proficient at putting as a whole. McLaughlin et al. (2008) did not publish data on CPE about the AP axis and Hurrion and Hurrion (2008) combined ML and AP CPE, therefore it is difficult to make exact comparisons to their datasets.

Increased CPE observed in HH golfers could be attributed to mechanisms discussed by Pelz (2000) regarding how the golf player generates power to project 
the ball toward the target. There are three recognized sources of power for a golf putt; a) the fingers, hands and wrists, b) forearm rotation (for players who use an arced stroke), and c) whole body rotation and movement. Body rotation in the current study was considered to be rotation of the torso around the spine (longitudinal axis). Pelz (2000) states of the three sources used to generate power, whole body rotation and movement is the least desirable, as the large muscles of the back, legs and chest are strong and difficult to control for the fine movement of putting, particularly when compared with the relatively small amounts of power needed for putting. If there is an increase in body movement it is likely that CPE will also increase. Delphinus and Sayers (2012) observed proficient golfers center of mass (COM) moved predominantly in the frontal plane (ML axis) whereas nonproficient golfers moved within the sagittal plane (AP axis) while also demonstrating greater movement variability. This suggests controlled repeatable movement in the ML direction will increase the proficiency of putting.

The CP will move in a similar direction to the COM as measured by Delphinus and Sayers (2012), however, the CPE is also dependent on the projection of the muscle forces required to produce the movement (Palmieri, Ingersoll, Stone \& Krause, 2002[AUQ1]), in this case the putting stroke. This may explain the results found in the current study, as increased CPE was found to occur about the AP axis for the $\mathrm{HH}$ group in comparison with the $\mathrm{LH}$ group, therefore the $\mathrm{HH}$ groups COM will have moved along the sagittal plane due to increased body movement. Increased variability of $\mathrm{CPE}$ about the AP axis for the $\mathrm{HH}$ group was also observed.

In certain cases, increased body movement may in fact reduce CPE. To keep the center of mass stationary, the golfer must move the body in directions opposite to that of the putter and arms. However, this is not applicable when referring to the AP axis as the putter and arms are predominantly translating along the ML axis. This suggests less proficient golfers have a reduced ability in controlling CPE in the AP direction, which will have a negative effect on performance. Another explanation for this may be the HH group's lack of understanding of how to execute a putting stroke. High handicap golfers may not consider movement about the AP axis undesirable and therefore may not try to control the movement.

The results of the current study are not in accordance with those of McLaughlin et al. (2008), who found significant differences to exist in CPE about the ML axis, whereas in the current study no significant differences were found for CPE about the ML axis between any of the three groups in all three phases of the putt. Differences in results between McLaughlin et al. (2008) and the current study may be due to the different lengths of putt tested, (the current study used $2.5 \mathrm{~m}$ and McLaughlin et al. (2008) used $4 \mathrm{~m}$ ). Hurrion and Hurrion (2008) also observed significantly less total CPE in European Tour professional golfers in comparison with LH golfers. Hurrion and Hurrion (2008) suggest that the smaller the CPE the greater the balance of the golfer during the golf putt. Hurrion and Hurrion (2008) and McLaughlin et al. (2008) found golfers with lower handicaps had significantly smaller CPE about the ML axis respectively, which contrasts with the findings of the current study that found significantly smaller CPE about the AP axis.

The findings of this study suggest that less variability associated with CPE about the AP axis contributes to being a more proficient putter. This may be due to having increased balance while still being able to effectively execute a putting stroke as suggested by Hurrion and Hurrion (2008). In the current study total CPE (ML and AP combined) was smaller than those observed by Hurrion and Hurrion (2008). 
Especially in Phase 3 where Hurrion and Hurrion (2008) observed combined CPE of $53.26 \mathrm{~mm}$ for an amateur group and $41.97 \mathrm{~mm}$ for a professional group compared with $15.36 \mathrm{~mm}$ for the LH group, $20.54 \mathrm{~mm}$ for the $\mathrm{MH}$ group and $30.97 \mathrm{~mm}$ for the $\mathrm{HH}$ group in the current study. Hurrion and Hurrion (2008) accredit this movement in the follow-through phase as a reaction to the impact as the player's head moves backward away from the target line, causing a sharp lift in the putter head during the follow-through. The reduction in CPE may be due to the different lengths of putts used in each study, Hurrion and Hurrion (2008) used a $7.6 \mathrm{~m}$ putt, and the current study used a putt of $2.5 \mathrm{~m}$.

The LH group demonstrated reduced CPE in the left foot for all three phases of the putt about the AP axis in comparison with the $\mathrm{HH}$ group. This was in contrast to the right foot where the LH only demonstrated significantly less CPE about the AP axis in phase 3 of the golf putt. This implies that the LH group is more able to control CPE by eliminating excessive movement about the AP axis in the lead foot in comparison with the $\mathrm{HH}$ group. Increased CPE in the lead foot may lead to more "miss hits" as it may alter the plane and potentially the face angle which Karlsen, Smith and Nilsson (2008) state accounts for $97 \%$ of stroke direction consistency.

McLaughlin et al. (2008) reported CPE to be independent to movement of the putter head, in the current study. This independent movement was found to exist for Phase 2 of the putting stroke (Figure 4). Greater right CPE was observed in comparison with left CPE, resulting in a trend toward the back foot whereas the putter is moving toward the front foot. As described by Pelz (2000), many elements contribute to a successful putt, which allows for a wide range of techniques from player to player. Therefore, studies with a larger cohort would be needed to confirm whether CPE is independent of putter movement as currently there is conflict within the literature.

It is worthy to note that CPE about both the ML and AP axis did not influence weight distribution as no significant differences were found between the three groups for any of the four swing events. At set up Hurrion and Hurrion (2008) found significant differences between a professional group (left $=48.34 \%$, right $=51.66 \%$ ) in comparison with a LH group (left $=40.37 \%$, right $=59.60 \%$ ). This differs from the current study, as there was a trend to place more weight on the left foot. However, similar to Hurrion and Hurrion (2008) all groups favored placing more weight on the forefoot. This is likely due to the ball being placed in front of the feet and thereby the golfer leans forward to execute the stroke. Extreme values favoring the forefoot may however reduce the ability to control balance. So as Hurrion and Hurrion (2008) suggested, most golfers would assume a comfortable stance and in certain cases this will reduce balance throughout the stroke, and the current study supports this statement.

A potential limitation of the current study is that performing golf shots in laboratory conditions is very different to an actual putt during a golf round and therefore may affect results. However, the subjects were allowed time to habituate themselves to the surroundings to minimize the effect as much as possible. Although the camera frame rate in the current study was adequate in identifying the putting phases no current research in the field of CPE during the putting stroke has been recorded using high-speed $(200 \mathrm{~Hz})$ video cameras identifying what body movements are causing CPE. Future research should investigate the relationship between CPE and post impact ball kinematics using high-speed camera technology. 
This will further knowledge in the field of golf putting kinematics and has the potential to explain why LH golfers have a lower putter head velocity.

\section{Conclusion}

Low handicap golfers demonstrate smaller CPE about the AP axis in comparison with the HH group in all three phases of the golf putt; this was also apparent for the left (lead) foot. No significant difference was found for CPE about the ML axis for all three phases of the golf putt or in weight distribution throughout the putting stroke. Results suggest that reduced CPE about the AP axis increases balance and subsequently improves the putting stroke. The practical implication of the study is that golfers should focus on reducing CPE about the AP axis to improve putting performance. In addition the findings of the study supports the use of training aids to encourage a 50/50\% weight distribution between the heel and forefoot to limit CPE about the AP axis during the putting stroke. Coaches should identify the golfer's body parts used to generate power, to eliminate unnecessary movement of the torso within the sagittal plane allowing for more control of the equilibrium and subsequently balance.

\section{References}

Delay, D., Nougier, V., Orliaguet, J.P., \& Coello, Y. (1997). Movement control in golf putting. Human Movement Science, 16(5), 597-619. doi:10.1016/S01679457(97)00008-0

Delphinus, E.M., \& Sayers, M.G.L. (2012). Putting proficiency: contributions of the pelvis and trunk. Sports Biomechanics, 11(2), 212-222. PubMed doi:10.1080/14763141.2011.638723

Dorsel, T.N., \& Rotunda, R.J. (2001). Low scores, top 10 finishes, and big money: An analysis of professional golf association tour statistics and how these relate to overall performance. Perceptual and Motor Skills, 92(2), 575-585. PubMed doi:10.2466/pms.2001.92.2.575

Hurrion, P.D., \& Hurrion, R.D. (2008). An investigation into weight distribution and kinematic parameters during the putting stroke. Crews, D., \& Lutz, R., editors. Science and golf V: Proceedings of the World Scientific Congress of Golf. Mesa, Arizona: Energy in Motion; pp. 223-238.

Hurrion, P. D., \& Hurrion, R. D. (2002). An investigation into the effect of the roll of a golf ball [AUQ2]

Thain, E., editor. Science and Golf IV: Proceedings of the World Scientific Congress of Golf. London: Routledge; pp. 531-538. [AUQ3]

Karlsen, J., Smith, G., \& Nilsson, J. (2008). The stroke has only a minor influence on direction consistency in golf putting among elite players. Journal of Sports Sciences, 26(3), 243-250. PubMed doi:10.1080/02640410701530902

MacKenzie, S.J., \& Sprigings, E.J. (2005). Evaluation of the plumb-bob method for reading greens in putting. Journal of Sports Sciences, 23(1), 81-87. PubMed doi:10.1080/02640410410001730232

McLaughlin, P., Best, R., \& Carlson, J. (2008). Movement of the centre of pressure (CPE) in the putting stroke. In: Crews, D., \& Lutz, R., editors. Science and golf $V$ : Proceedings of the World Scientific Congress of Golf. Mesa, Arizona: Energy in Motion; pp. 239-244.

Pelz, D.T. (2000). Dave Pelz's Putting Bible. New York: Random House. 
Quinn, R. J. (2006). Exploring correlation coefficients with golf statistics. Teaching Statistics, 28(1), 10-13 1467-9639.

Ruhe, A., Fejer, R., \& Walker, B. (2011). Center of pressure excursion as a measure of balance performance in patients with non-specific low back pain compared to healthy controls: A systematic review of the literature. European Spine Journal, 20(3), 358-368. PubMed doi:10.1007/s00586-010-1543-2

Schmidt, R.A., Zelaznik, H.N., Hawkins, B., Frank, J.S., \& Quinn, J.T. (1979). Motoroutput variability: A theory for the accuracy of rapid motor acts. Psychological Review, 86(5), 415-451. PubMed doi:10.1037/0033-295X.86.5.415

Sim, M., \& Kim, J.U. (2010). Differences between experts and novices in kinematics and accuracy of golf putting. Human Movement Science, 29(6), 932-946. PubMed doi:10.1016/j.humov.2010.07.014

Steinberg, G.M., Frehlich, S.G., \& Tennant, L.K. (1995). Dextrality and eye position in putting performance. Perceptual and Motor Skills, 80(2), 635. PubMed doi:10.2466/pms.1995.80.2.635 [AUQ4]

Wilson, M.R., \& Pearcy, R.C. (2009). Visuomotor control of straight and breaking golf putts. Perceptual and Motor Skills, 109(2), 555-562. PubMed doi:10.2466/pms.109.2.555-562 [AUQ5]

Wiseman, F., \& Chatterjee, S. (2006). Comprehensive analysis of golf performance on the PGA tour: 1990-2004. Perceptual and Motor Skills, 102(1), 109-117. PubMed doi:10.2466/pms.102.1.109-117

Figure 1 - The three phases of the putting stroke.

Figure 2 - RS FootScan screen shot depicting the typical segmentation of the putting stance.

Figure 3 - Putting success rate for the LH, MH and HH groups. *Significant difference between $\mathrm{LH}$ and HH group $(\mathrm{p}<0.05)$, ${ }^{\dagger}$ Significant difference between the $\mathrm{LH}$ and $\mathrm{MH}$ group $(\mathrm{p}<0.05){ }^{\S}$ Significant difference between the MH and HH group $(\mathrm{p}<0.05)$.

Figure 4 - Relative CPE patterns for A) Start to Top of Backswing phase, B) Top of Backswing to Impact phase, $C)$ Impact to Follow-through phase ( $A=$ anterior, $M=$ medial, $\mathrm{P}=$ posterior, $\mathrm{L}=$ lateral). 
Table 1 Total, left and right foot center of pressure excursions (mean $\pm S E$ ) for Phase 1) Start to Top of Backswing, Phase 2) Top of Backswing to Impact, phase 3) Impact to Follow Through.

\begin{tabular}{|c|c|c|c|c|c|c|c|}
\hline & & \multicolumn{2}{|c|}{ Total Body CPE } & \multicolumn{2}{|c|}{ Left Foot CPE } & \multicolumn{2}{|c|}{ Right Foot CPE } \\
\hline & Group & $\begin{array}{l}\text { Anterioposteri } \\
\text { or }(\mathrm{mm})\end{array}$ & $\begin{array}{l}\text { Mediolateral } \\
(\mathrm{mm})\end{array}$ & $\begin{array}{c}\text { Anterioposterio } \\
r(\mathrm{~mm})\end{array}$ & $\begin{array}{l}\text { Mediolateral } \\
(\mathrm{mm})\end{array}$ & $\begin{array}{c}\text { Anterioposterior } \\
(\mathrm{mm})\end{array}$ & $\begin{array}{l}\text { Mediolateral } \\
(\mathrm{mm})\end{array}$ \\
\hline \multirow[t]{3}{*}{ Phase 1} & LH & $4.90 \pm 0.44 *$ & $14.146 \pm 2.37$ & $7.53 \pm 0.61 *^{\dagger}$ & $2.80 \pm 0.33^{* \dagger}$ & $8.23 \pm 1.03^{\dagger}$ & $3.65 \pm 0.64$ \\
\hline & $\mathrm{MH}$ & $8.57 \pm 1.03$ & $18.65 \pm 3.75$ & $13.82 \pm 2.31^{\dagger}$ & $5.13 \pm 0.76^{\dagger}$ & $12.83 \pm 2.22^{\dagger}$ & $4.12 \pm 0.63$ \\
\hline & $\mathrm{HH}$ & $8.97 \pm 1.32 *$ & $15.63 \pm 2.97$ & $17.31 \pm 2.44^{*}$ & $4.69 \pm 0.55$ & $11.01 \pm 1.06$ & $4.07 \pm 0.80$ \\
\hline \multirow[t]{3}{*}{ Phase 2} & LH & $2.76 \pm 0.87 *$ & $8.14 \pm 2.24$ & $4.35 \pm 0.36^{*}$ & $1.69 \pm 0.27 *$ & $5.01 \pm 0.53$ & $2.00 \pm 0.37$ \\
\hline & MH & $6.00 \pm 1.40$ & $8.81 \pm 1.33$ & $7.70 \pm 1.31$ & $2.66 \pm 0.41$ & $8.75 \pm 2.27$ & $2.40 \pm 0.55$ \\
\hline & $\mathrm{HH}$ & $9.95 \pm 3.11 *$ & $15.23 \pm 6.99$ & $11.50 \pm 2.54^{*}$ & $3.15 \pm 0.62 *$ & $8.62 \pm 1.28$ & $2.27 \pm 0.42$ \\
\hline \multirow[t]{3}{*}{ Phase 3} & LH & $4.51 \pm 0.42 *$ & $10.88 \pm 1.01$ & $6.33 \pm 0.32 *$ & $2.25 \pm 0.18^{* \dagger}$ & $7.04 \pm 0.91 *$ & $2.78 \pm 0.22$ \\
\hline & MH & $7.13 \pm 0.69$ & $13.41 \pm 3.04$ & $11.11 \pm 0.88$ & $4.24 \pm 0.31^{\dagger}$ & $12.77 \pm 1.41$ & $3.49 \pm 0.28$ \\
\hline & $\mathrm{HH}$ & $13.12 \pm 3.40 *$ & $17.85 \pm 7.19$ & $15.23 \pm 2.66^{*}$ & $4.08 \pm 0.51 *$ & $13.77 \pm 2.00 *$ & $3.26 \pm 0.49$ \\
\hline
\end{tabular}

* Significant difference between LH and HH group $(\mathrm{p}<0.05)$, ${ }^{\dagger}$ Significant difference between the LH and MH group $(\mathrm{p}<0.05)$. 


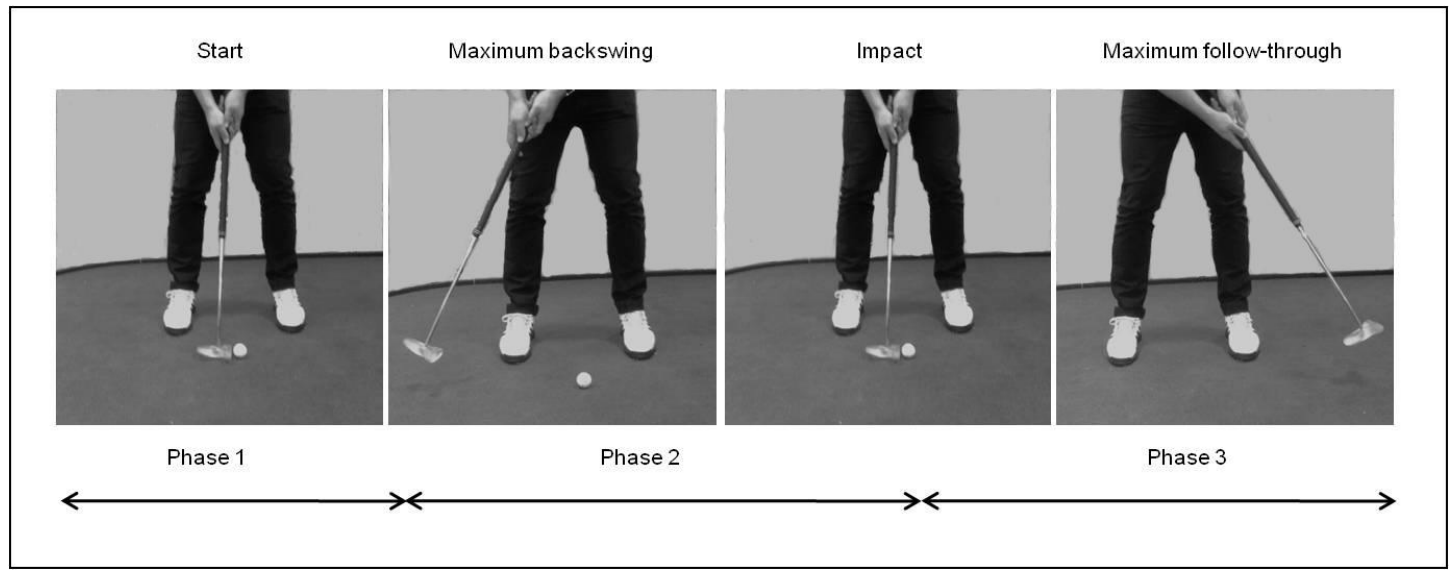

Fig 1

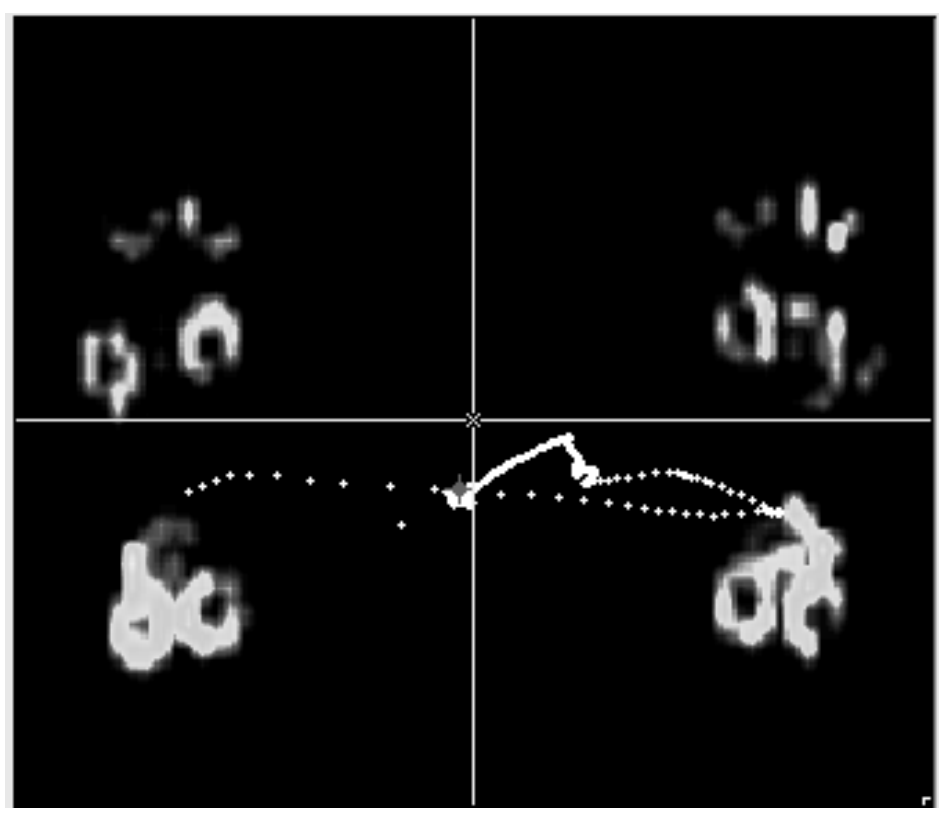

Fig 2

Page 12 of 15 


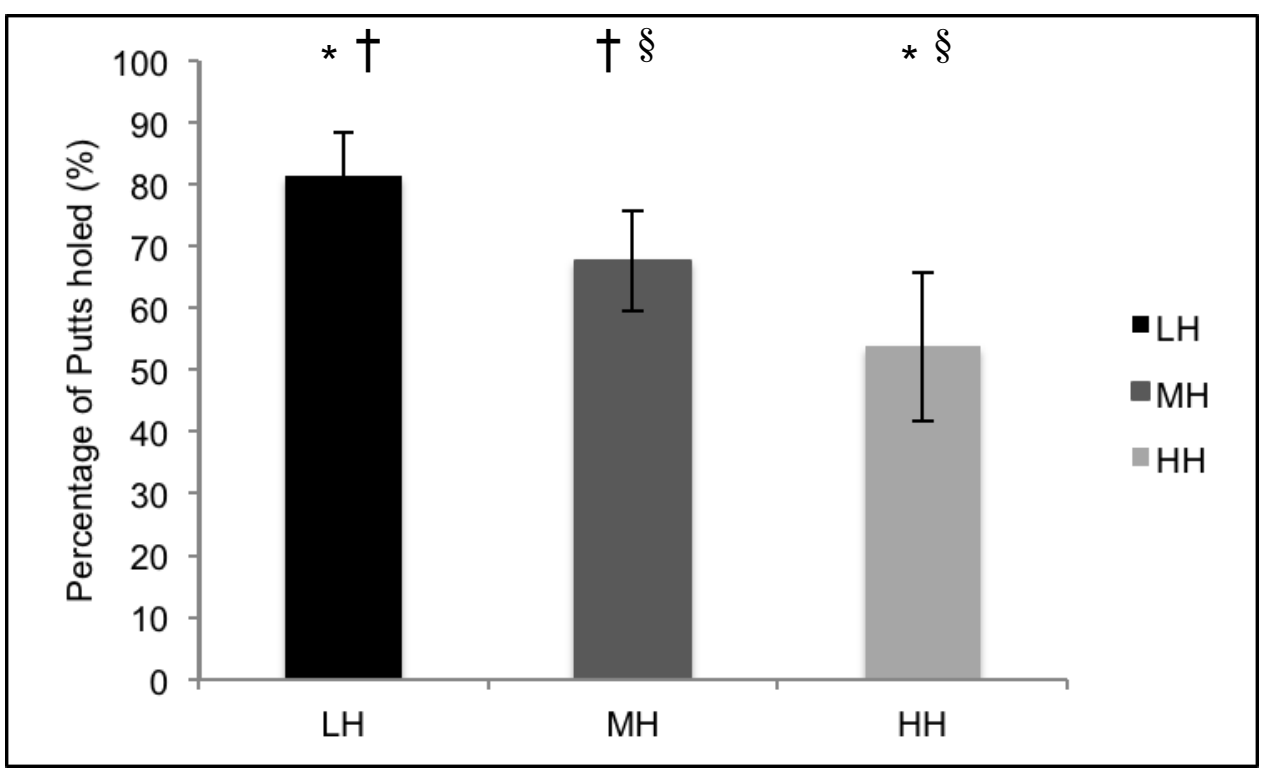

Fig 3

Page 13 of 15 


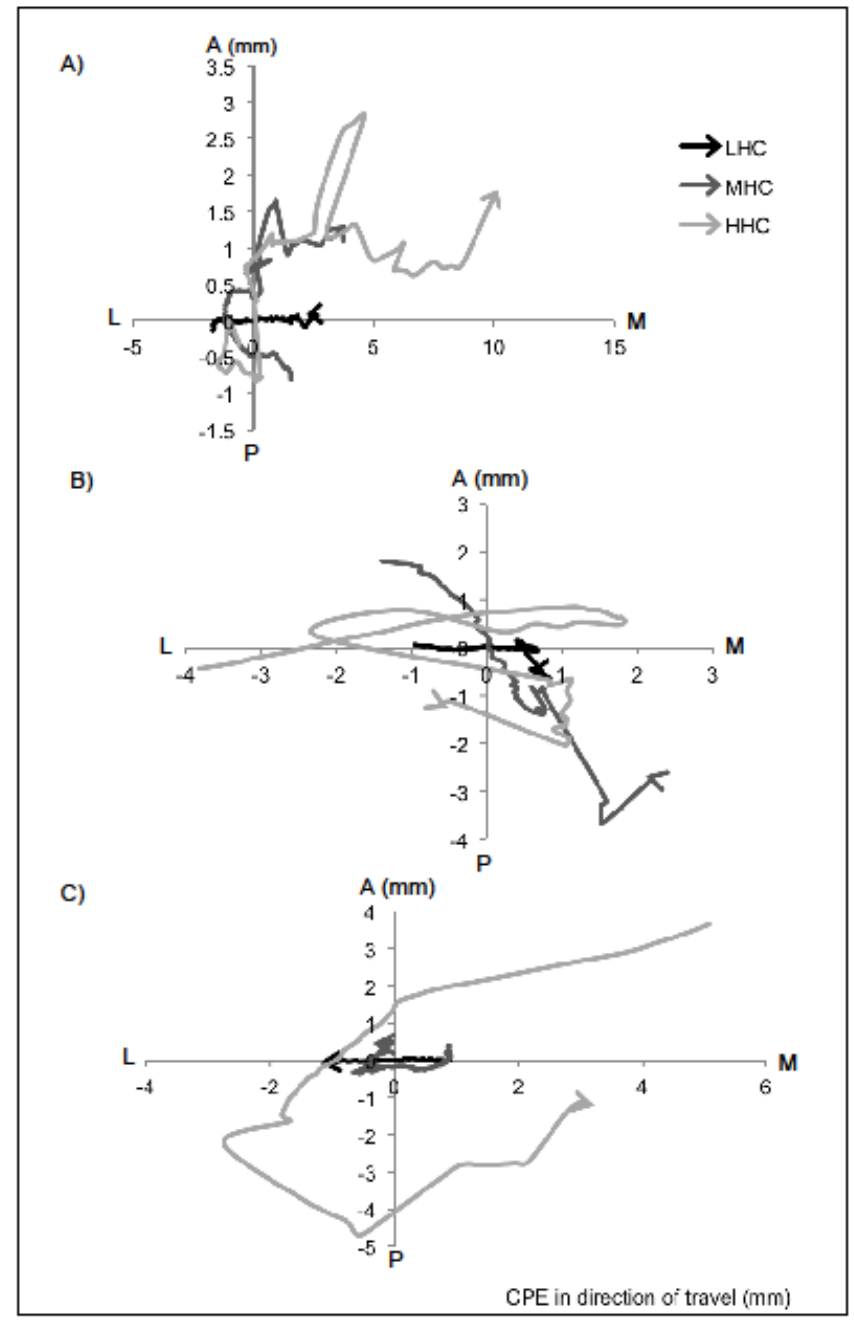

Fig 4

Page 14 of 15 


\section{Author Queries}

[AUQ1] The in-text citation "Palmieri, Ingersoll, Stone \& Krause, 2002" is not in the reference list. Please correct the citation, add the reference to the list, or delete the citation.

[AUQ2] Reference "Hurrion, Hurrion, 2002" is not cited in the text. Please add an in-text citation or delete the reference.

[AUQ3] Reference "Thain" is not cited in the text. Please add an in-text citation or delete the reference.

[AUQ4] Reference "Steinberg, Frehlich, Tennant, 1995" is not cited in the text. Please add an in-text citation or delete the reference.

[AUQ5] Reference "Wilson, Pearcy, 2009" is not cited in the text. Please add an in-text citation or delete the reference. 